\title{
Do E-books offer Enhanced Learning Experiences for Engineering Students?
}

\author{
Sharon Murphy \\ Head, Engineering \& Science Library \\ Queen's University \\ murphys@queensu.ca
}

\author{
Nasser Saleh \\ Integrated Learning Librarian \\ Queen's University \\ nasser.saleh@queensu.ca
}

\begin{abstract}
This paper provides an outline of a planned study by Queen's University Engineering \& Science Library about the current suite of e-book content, formats and functionality available, notably to engineering students and how they access, read, manipulate and share the content to enhance their learning. As well, we will investigate some instructors' usage of these collections
\end{abstract}

\section{Introduction}

Engineering students access a broad range of information resources in the course of study and research. They use technical articles, reports, regulations, standards, patents and books in different formats whether they are in print or electronic. Of all of the foregoing, it is books that have been the slowest to become available in useable electronic formats. But that is changing. In the 2010 edition of EDUCAUSE's Horizon Report on emerging technologies, they write that electronic books (ebooks) have reached "mainstream adoption in the consumer sector" [1] and the report predicts that ebooks are just 2-3 years away from mainstream status for academic use. The uptake is due to improved content and usability.

At Queen's University, the library spends less than $5 \%$ of the Engineering \& Science annual collections budget on print books. Instead, preference is always given to books in electronic format. This practice reflects the preference of most of our students for digital resources wherever possible.

We buy publisher packages like Springer and CRC, multiple publisher aggregations like Knovel, and we can select on a title by title basis. Most of our collection is available in PDF format and so is readable on any device with Adobe. Readers can use the interface at the publishers' site or an e-reader. For example we use ebrary for books bought with the
Ontario Council of University Libraries (OCUL) consortium. This interface allows students to create a personalized bookshelf of books marked up with notes and annotations which can be shared by email with others and exported to bibliographic management software such as Refworks. Some publishers' interfaces are noteworthy. Knovel, with its strong handbook collection, in addition to customization, offers data searching and export. Several university libraries are loaning e-book readers, some loaded with content for their students. [1].

It remains a challenge to make students aware that e-books are available to them [2]. At Queen's we enter individual book titles in our catalogue, link to ebook sets from our web pages and imbed e-book search widgets on web pages and in course management software. For example, we have search boxes to our catalogue and Knovel in Moodle for engineering students. While our print circulation statistics have been in decline for several years, the use statistics for e-books are quite good. So, we have evidence that e-books are used, but do they use them well?

\section{Method}

As the library can only determine the usage of ebooks through monthly and annual quantitative statistics provided by collection providers and publishers of the collections that the library subscribes to, it is crucial to know how well these collections are used and what is the students' experience in using them. We also need to know what enhanced features of e-books they use and what they expect to get from using e-books. Also, we need to know whether engineering professors are using ebooks as part of their course readings and how often they refer students to e-books, the study will constitute of four main parts:

1. Literature review: a review of recent literature on using e-books in academic 
libraries and the awareness level of both faculty and students about the availability and usage of e-books within the curriculum of undergraduate studies with a focus on specific results from engineering students and professors if there are any.

2. Environmental scan: a descriptive statistical analysis of the current landscape of e-books collections that available to engineering students at Queen's university, the environmental scan will compare the features of different products and also what statistical benchmarks are common among those provided statistical reports. The environmental scan will also incorporate some of the results of LIBQUAL, a survey to students and faculty that took place in 2010, to determine if there are incidents within these responses regarding e-books.

3. Web-based survey: a web-based survey will be sent to engineering students during the academic year of 2010/11 to get more insights about their usage of e-books and another web-based survey will be sent to engineering professors to measure their awareness of the availability of e-books in the library collections and if they have used them as a part of their courses. Both surveys will have multiple choice questions in addition to open ended questions to gather date on e-books awareness, usages, and perceptions.

4. Focus group: we plan to have a focus group of engineering students to get more qualitative data about students' awareness and usage of e-books for their undergraduate course. The invitation to participate in the focus group will be included in the webbased survey and will be coordinated with the engineering society at Queen's faculty of engineering and applied science.

\section{Discussion}

As noted from the literature, there were very few studies that aimed to investigate the impact of ebooks in academic libraries [2]; particularly in the field of engineering. The growing numbers of available e-books to engineering students is seen to affect students' perceptions towards e-books given the growth of e-books collections.
Also there is a need to understand how the different formats of books and functionality would impact users experience and if some features would more attractive than others such as the enhanced data features from some collections such as Knovel.

We also need to get into more qualitative date from both faculty and students so we can define our strategy towards subscription to e-book package, a few of the comments about books from science and engineering respondents from our recent LIBQUAL survey:

"E-books are always a good bet."

"I would like to have access to more electronic books”

And, our favorite response: "Nobody uses [print] books anymore, catch up.”

\section{Conclusion}

The planned study is important for both professors and academic engineering librarians. Librarians need to know if the currently subscribed e-book collections are used or not and if they are used, what type of usage and experience students have. Also, engineering professors can become aware of the availability of these resources and then can play a significant role ensuring that students are making to most of the content and features of e-books by embedding search boxes and linking to readings online, and by demonstrating examples from books. Other opportunities are giving problems requiring use of these books and include their use in assessment. The study can be significant to other academic libraries that may have the same questions and it will be an opportunity, if we can have other academic libraries participate in this study, to benchmark awareness and usage of e-book in engineering undergraduate curriculum among different Canadian universities.

\section{References}

[1] EDUCAUSE, "Electronic Books" in The Horizon Report, 2010, 17-20: http://www.nmc.org/pdf/2010Horizon-Report.pdf

[2]W. Shelburne, "E-book usage in an academic library: user attitudes and behaviors", Library Collections, Acquisitions, \& Technical Services 33, 2009, 59-72. 